\title{
Measuring urban vulnerability to climate change using an integrated approach, assessing climate risks in Beijing
}

\author{
Mingshun Zhang ${ }^{\text {Corresp., }}{ }^{1}$, Zelu Liu $^{1}$, Meine Pieter van Dijk ${ }^{2}$ \\ ${ }^{1}$ Beijing Climate Change Response Research and Education Centre, Beijing University of Civil engineering and Architecture (BUCEA), Beijing, China \\ 2 International Institute of Social Studies (ISS), Erasmus University Rotterdam, The Hague, the Netherlands \\ Corresponding Author: Mingshun Zhang \\ Email address: zhangmingshun@bucea.edu.cn
}

This study is responding to the recommendation made by IPCC's fifth Assessment Report on establishing a standard for measuring and reporting climate risk and vulnerability. It exemplifies the assessment of urban vulnerability to climate change by an integrated approach. The results indicate that Beijing is highly exposed to multiple climate threats in the context of global climate change, specifically urban heat waves, urban drainage floods and drought. Vulnerabilities to the climatic threats of heat waves, drainage floods and droughts have increased by $5 \%-15 \%$ during the period of 2008-2016 in Beijing. High vulnerabilities to both heat waves and drainage floods have been observed in the urban downtown area and high vulnerability to droughts have been observed in the outskirts. This vulnerability assessment, which addressed climatic threats, provides a holistic understanding of the susceptibility to climate change that could facilitate adaptation to climate change in the future. The developments of threats like flooding, heat waves and droughts are analyzed separately for 16 districts and an integrated vulnerability index for all of Beijing is provided as well. 
1 Measuring urban vulnerability to climate change using an integrated approach, 2 assessing climate risks in Beijing

3

4

5

6

7

8

9 10

Mingshun Zhang ${ }^{1}$, Zelu Liu ${ }^{1}$, Meine Pieter van Dijk ${ }^{2}$

${ }^{1}$ Beijing Climate Change Response Research and Education Centre, Beijing University of Civil engineering and Architecture (BUCEA), Beijing, China

${ }^{2}$ International Institute of Social Studies (ISS), Erasmus University Rotterdam, the Netherlands

Corresponding Author:

Mingshun Zhang

No.1 Zhanlanguan Road, Beijing, 100044, China

Email address: zhangmingshun@bucea.edu.cn

\section{ABSTRACT}

This study is responding to the recommendation made by IPCC's fifth Assessment Report on establishing a standard for measuring and reporting climate risk and vulnerability. It exemplifies the assessment of urban vulnerability to climate change by an integrated approach. The results indicate that Beijing is highly exposed to multiple climate threats in the context of global climate change, specifically urban heat waves, urban drainage floods and drought. Vulnerabilities to the climatic threats of heat waves, drainage floods and droughts have increased by 5\%-15\% during the period of 2008-2016 in Beijing. High vulnerabilities to both heat waves and drainage floods have been observed in the urban downtown area and high vulnerability to droughts have been observed in the outskirts. This vulnerability assessment, which addressed climatic threats, provides a holistic understanding of the susceptibility to climate change that could facilitate adaptation to climate change in the future. The developments of threats like flooding, heat waves and droughts are analyzed separately for 16 districts and an integrated vulnerability index for all of Beijing is provided as well.

\section{INTRODUCTION}

A vulnerability assessment can be a useful tool for providing information about where we are with regard to the development of the adaptive capacity of a city and the adaptation activities of the population with respect to climate change [9].The United Nations Framework Convention on Climate Change (UNFCCC) notes that "adaptation emerged as a focus area under the United Nations Framework Convention on Climate Change (UNFCCC) in 2001. However, the attention given to it is still not equal to mitigation with regard to target-setting, financing, and institutional frameworks". By establishing an explicit long-term adaptation goal in Article 7, the Paris Agreement [1] builds on an international consensus on the need of vulnerability reduction and confirms that adaptation to climate change is a key pillar of UNFCCC. Magnan and Ribera 
41

42

43

44

45

46

47

48

49

50

51

52

53

54

55

56

57

58

59

60

61

62

63

64

65

66

67

68

69

70

71

72

73

74

75

76

77

78

79

80

observe as a challenge that climate change adaptation achieves "equal prioritization with mitigation (given) the relative fuzziness of adaptation as a policy area" [2]. Ford adds that "mitigation policy constitutes a response to a clear problem (GHG emissions) and can be measured and tracked using standardized and accepted indicators (e.g. tons of carbon). In contrast, adaptation is difficult to define and track, especially in relation to policy issues like development or disaster risk management" [3]. Adaptation is place- and context-specific, with no single approach for reducing risks appropriate across all settings [4]. Vulnerability to climate change can be an accepted indicator for measuring and tracking the success of the adaptation process.

A large and diverse literature has emerged how to assess vulnerability to climate change. The common challenges are to develop robust and credible measures using indicators and indices (known as indicator-based vulnerability assessment (IBVA)) at international, national and local levels [5, 23]. Since climate change vulnerability assessment is a complex form of risk assessment, indicators to be used cover components of both geophysical and socio-economic systems [6]. Unlike a single system, complex geophysical and socio-economic systems requires large number of indicators for capturing all aspects of vulnerability, and thus all IBVA approaches are facing challenges of selection of necessary indicators, aggregation of indicators into an index, linking indicators to policy implication [7].

There are two methods for aggregating single indicators into indices in the literature. One is weighting single indicators, and the other is non-weighting single indicators. Weighting means that all single indicators will have different contributions to the integrated index, while nonweighting means that all single indicators have the same contributions to the integrated index. Weights are the measures of importance. There are three arguments for weighting indicators. (a) It is priority-based, and tends to be more realistic than non-weighted indicators. By weighting, priority issues can be addressed and emphasized, and reasonable judgments and decisions can be made. This is very important for the efficient distribution of available resources, and identifying key issues that all stakeholders are concerned about and agree upon. (b) It avoids loss of information during the indicators' aggregation as much as possible. It is obvious that key indicators will have more weights than others, and aggregated index will have close linkages to the key indicators. The most relevant information will be used in the final index. (c) It is participation-based. Weighting process requires public participation for making judgment. Experts, stakeholders as well as citizens may be involved in the weighting process, and their opinions will have significant influence on the weights of indicators. Since there is no precise mathematical relationship between indicators that ultimately indicate or measure vulnerability, there are limitations in weighting geophysical and socio-economic indicators in measuring vulnerability [6]. Weighting indicators make more sense at local level. However, the complexity of issues and the lack of scientific weighting methodologies have been obstructing the application of weighting indicators $[8,19]$. Environmental indicators can be aggregated by 
81 weighting according to their contribution to the environmental issues, which can be determined 82 by scientific research. However, it is very difficult to integrate economic and social indicators by 83 weighting. This is why weighting indicators have not yet been commonly used in the aggregation 84 of social and economic indicators. In our research, the Analytical Hierarchy Process (AHP) has 85 been applied, together with expert judgment for integrating weighted indicators into the index of 86 vulnerability. We find that this method is useful for cities like Beijing, where there is a lack of 87 data, where the situation may differ in different locations and where it is impossible to use a 88 large numbers of indicators for measuring vulnerability to climate change.

89

90

91

92

93

Two questions remain in measuring vulnerability. The first concerns "the identification of appropriate reference points from which to assess whether we are successfully enhancing adaptive capacity, strengthening resilience and reducing vulnerability to climate change" (Article 7, para 2, the Paris Agreement). Reference points in emission reduction target-setting have been identified by the Kyoto Protocol and Paris Conference. However setting a reference point for adaptation requires much more and diverse information. The second question concerns the review processes for assessing vulnerability and thus measuring progress on adaptation commitments. It "will need to balance robustness and comparability of units or indicators that capture key aspects of vulnerability and adaptive capacity with being contextually appropriate" [2]. "Transparent and consistent decision-making on climate financing will require clarity on how adaptation intersects with broader development and risk reduction efforts, and thus what constitutes a progression beyond previous efforts" (Article 9, para 3, the Paris Agreement).

To assess vulnerability, it is crucial to define vulnerability. The most authoritative and widely quoted definition of vulnerability in the context of climate change is developed by the Fourth Assessment Report of the Intergovernmental Panel on Climate Change (IPCC) [10].

"Vulnerability is the degree to which a system is susceptible to, and unable to cope with, adverse effects of climate change, including climate variability and extremes. Vulnerability is a function of the character, magnitude, and rate of climate change and variation to which a system is exposed, its sensitivity, and its adaptive capacity". The IPCC definition has significant limitations. Most critically the three components of exposure, sensitivity and adaptive capacity have not been clearly defined and thus the challenge is to develop indicators for measuring the three components mentioned-above. Patt observes that "The IPCC concept in general has proven difficult to operationalize in practice" [11]. There is considerable debate in the literature as to what constitutes adaptive capacity and how it might be recognized [12, 13, 14].

A city is a complex system composed of multiple sub-systems that interact in various and often crucial ways [15]. Vulnerability related to climate change corresponds with risks of all subsystems in climate change. However, if measuring vulnerability wants to take all dimensions of vulnerability into account, a considerable number of indicators for measuring of vulnerability is required. The challenge is to deal with two controversial issues. One, the growing complexity of

Peer) reviewing PDF | (2019:02:35170:2:1:NEW 23 Apr 2019) 
121 the definition of urban vulnerability related to climate change and secondly, the practical demand

122 for simplicity of information concerning vulnerability. There is no consensus how many

123 indicators are needed for effective measurement of urban vulnerability. The point is to identify

124 the essential elements that could capture the relevant information on the total system.

125

Main challenges for development of vulnerability assessment include (1) lack of data availability or gaps in the data, (2) integrating different sources of information (e.g. peer-reviewed and grey literature, quantitative data with qualitative information and expert judgment), (3) development and use of a unified methodology (e.g. common climate scenarios, metrics), (4) involvement of stakeholders, (5) collection of information is expensive in terms of time and resources and (6) development of effective indicators [16]. This article addresses the mentioned-above challenges of (1) - (4).

133

The concept of vulnerability is complex and a one dimensional approach could not meet the needs of vulnerability assessment. Hence an integrated approach is necessary. This article is concerned with creating an urban vulnerability index (UVI) following a step-by-step approach in the context of urban China and intends to help policy-makers at the city and district levels to get insight in the factors determining vulnerability by measuring the progress achieved in adaptation to climate change in the urban areas. Our strategy is first to develop an urban vulnerability index, and secondly to measure empirically the UVI in Beijing, the capital city of China and its major districts. It is the first time such an assessment of vulnerability to climate change is taking place in Beijing, although there are various natural disaster risk assessments reported that use two single indicators (economic damages and mortality) without weighing. The methods developed in this research can become a useful tool for other emerging cities as well.

\section{UVI DEVELOPMENT: THEORY AND DATA COLLECTION METHOD}

The major research question is in which way we can measure urban vulnerability in Beijing. Subquestions concern the role of floods, the role of heat waves and the role of droughts. Kropp [17] developed heat wave indicator within the scope of a climate change vulnerability study for North Rhine Westphalia. However this indicator does not cover the three components of exposure, sensitivity and adaptive capacity. In our research, we propose that vulnerability could be assessed by the dimensions of exposure, sensitivity and adaptive capacity. Exposure is determined solemnly by climatic threats or issues (e.g. heat wave, urban flooding, drought, etc.). The sensitivity is determined by characteristics of sectors, systems and group of people that are directly or indirectly influenced by climatic threats. The adaptive capacity of a system is determined by the system's capacity to adjust to climatic threats including the ability to learn from experience or information and hence to reduce its sensitivity. Both exposure and sensitivity lead to more vulnerability, while increased adaptive capacity diminishes vulnerability. Figure 1 shows the procedures we developed to guide the assessment of vulnerability. We separate the procedure to do the assessment from the methods used to come up with the necessary data. 
161

162

163

164

165

166

167

168

169

170

171

172

173

174

175

176

177

178

179

180

181

182

183

184

185

186

187

188

189

190

191

192

193

194

195

196

197

198

199

200

Fig. 1 Procedures for the assessment and methodology for data collection

Climate change has different meaning for different cities and different cities face different priority climate themes. In this study, Impact Oriented Monitoring (IOM), together with stakeholders' participation is applied to identify key climatic threats or priority climate themes that Beijing is facing. IOM is based on historical data of direct economic loss of climatic events, in particular the data concerning the last 12 years in the Beijing Annual Natural Disaster Report. Following the identification of priority climate themes, a one day workshop was organized by the Beijing Climate Change Response Research and Education Centre, of the Beijing University of Civil engineering and Architecture for allowing expert judgment and stakeholders' participation for identifying vulnerable sectors and groups. Title of this workshop was Vulnerable Sector and Groups: How Beijing Adapt to Climate Change and it took place on 14 April 2017. 30 participants attended the workshop. Among the 30 participants who are all senior experts, 24 ( 2 from each sector) are from sectors like water supply and sewage, waste management, public health, energy supply, urban green and biodiversity, forest and ecosystem, tourism, nature conservation, information and communication, insurance, transportation and education and 6 are experts recommended by China National Expert Committee on Climate Change Adaptation (CECCCA). Participants were selected on criteria like 1) at least 5 years working experiences in natural disaster governance or climate adaptation, 2) good knowledge of indicator development and index processing, 3) have participated in development of its sectoral strategies and policies on climate change adaptation. Before making a judgment participants listened to a presentation of this research and were discussing vulnerability issues allowing an intensive exchange of ideas between stakeholders and experts.

A two-steps approach was applied for the preliminarily selection of individual indicators. The first step is to do a literature review selecting individual indicators for climatic threats related vulnerable systems/sectors and vulnerable groups/individuals. By the literature reviews, we have selected preliminary 26 individual indicators for assessing urban vulnerability to the threat of floods, 32 indicators for assessing urban vulnerability to the threat of heat waves and 29 individual indicators for assessing vulnerability to the threat of drought. All those preliminary selected 87 indicators, together with a brief description of each indicator were distributed to the participants before the workshop. The second step is to adopt an expert approach and achieve stakeholders' participation as described above. The experts and stakeholders present their own understanding and comments and finally they make their own scoring for each of indicators, based on the criteria: 1) the indicators are closely related to the issue, 2) they are independent of one another, 3) relevant in the context of Beijing, 4) measurable and 5) the data are available. Based on the sum of the scores of each indicators, the final 23 indicators were selected for measuring urban vulnerability. 
201 A frequently mentioned challenge in indicator programmes [18] is how the index's inputs should 202 be weighted. In most of international indicator programmes, nominally all inputs into an index 203 receive equal weight. No indicator gets more weight than any other. An environmental 204 sustainability index programme implemented jointly by the World Economic Forum's global 205 Leaders for Tomorrow Environment Task Force, the Yale Center for Environmental Law and 206 Policy, and the Columbia University Center for International Earth Science Information Network 207 (CIESIN) has also addressed the issue of weighting indicators [19]. However the result is not 208 acceptable for two reasons. One is that weights identified by different experts from different 209 countries are very likely to differ significantly. This is because the situation is different from one 210 country to another. Another reason for getting poor results is probably that vulnerability is a complicated issue and may lead to confusion among different experts. The reason for opting for a weighting approach for the aggregation of the selected indicators are twofold. One to allow cross-urban comparisons. Most Chinese cities are quite similar in terms of climatic threats, economic growth, social progress, institutional capability and governance. Therefore a

215

216

217

218

219

220

221

222

223

224

225

226

227

228

229

230

231

232

233

234

235

236

237

238

239

240 scientifically acceptable determination of the weights should be achieved. Secondly we used the Analytical Hierarchy Process (AHP) method, together with consultation of experts. One of the main advantages of the AHP is that it allows experts to compare two factors by using the same criteria and scoring rule. As the identification with the same criteria and scoring rule is quite simple, statistical results can easily be obtained at an acceptable level. As an example, figure 2 shows how AHP is applied to aggregate weighted indicators into urban sensibility index that is one component of urban vulnerability for the threat of floods.

Fig 2 AHP framework for measuring urban sensibility for the threat of floods

As shown in figure 2, the AHP objective (first hierarchy) is to measure urban sensibility for the threat of floods under three principles (second hierarchy) of 1) relevance, 2) scientifically sound and 3) applicable to users by using weighted individual indicators (third hierarchy) of annual rainstorm hours (indicator 1), percentage of paved area (indicator 2) and risk of secondary disasters caused by heavy precipitation (indicator 3). Relevance is explained as directly related to the issue, based on a known linkage between the indicator and sensibility and sensitive to changes in the conditions of interest. Scientifically sound is explained as unbiased and representative of the conditions of concern, scientifically credible, so that they cannot be easily challenged in terms of their reliability or validity, based on data of a known and acceptable quality and consistent and comparable over time and space. Applicable to users is explained as based on data which are available at an acceptable cost-benefit ratio, easily understood and applicable by potential users, acceptable to stakeholders and available soon after the event or period to which it relates (so that policy decisions are not delayed). Experts and stakeholders compare the three individual indicators against each of the three principles by using the AHP scoring rule in table 1. 
241

242

243

244

245

246

247

248

249

250

251

252

253

254

255

256

257

258

259

260

261

262

263

264

265

266

267

268

269

270

271

272

273

274

275

Table 1 Values of comparison between two factors

Likewise, the urban exposure index and the urban adaptive capacity index can be calculated by weighted indicators and the urban vulnerability index can be weighted by giving weight to urban sensibility, urban exposure and urban adaptive capacity.

The composite UVI combines numbers of individual indicators measured in different units into a single number between 0 and 1. Kropp [17] uses fuzzy logic techniques for this combination in order to account for a quantification of uncertainties. Kropp notes that "these techniques allow for gradual instead of binary allocation of variable values to classes". For example in a region where life expectancy of 25 years old is classified as low and life expectancy of 85 years old is classified as high. A practical value in between these two thresholds is then allocated to the class 'life expectancy' according to a linear function that could for example result in the number ' 0.5 ' for the value 55 years old.

For applying fuzzy logic techniques, we developed the methodology for standardizing data aiming at generating the value of each of the indicators in a range from 0-1.

Standardized data is calculated by:

$$
\begin{aligned}
& I_{i}=\left(X_{i}-B_{i}\right) /\left(A_{i}-B_{i}\right)\left(\text { if } I_{i} \text { is a positive indicator. } i=1,2,3, \ldots, n\right) \\
& I_{i}=\left(B_{i}-X_{i}\right) /\left(B_{i}-A_{i}\right)\left(\text { if } I_{i} \text { is a negative indicator, } i=1,2,3, \ldots, n\right)
\end{aligned}
$$

Where:

$\mathrm{I}_{\mathrm{i}}$ : $\quad$ Standardized version of an indicator $\mathrm{I}_{\mathrm{i}}$. It varies from 0 to 1 .

$\mathrm{X}_{\mathrm{i}}$ : $\quad$ Real value of an indicator $\mathrm{I}_{\mathrm{i}}$;

$\mathrm{A}_{\mathrm{i}}$ : Theoretically max. value of a positive indicator $\mathrm{I}_{\mathrm{i}}$ and theoretically min. value of a negative indicator $\mathrm{I}_{\mathrm{i}}$.

$B_{i}$ : Theoretically min. value of a positive indicator $I_{i}$ and theoretically max. value of a negative indicator $\mathrm{I}_{\mathrm{i}}$.

Beijing has a population of 22 million and covers an area of $16400 \mathrm{~km}^{2}$. The city of Beijing is divided into four areas with 16 districts. Forced by the availability of statistical data, collected mainly by the district statistical bureaus, the research unit is the district, as presented in table 2 .

Table 2 Four areas and 16 districts under this research

\section{EMPIRICAL RESULTS}

3.1 Priority climate schemes

Based on the data of the past 12 years on economic damages of main climatic events (20052016), IOM is used to identify priority climatic threats in Beijing. Owing to the fact that those

PeerJ reviewing PDF | (2019:02:35170:2:1:NEW 23 Apr 2019) 
276

277

278

279

280

281

282

283

284

285

286

287

288

289

290

291

292

293

294

295

296

297

298

299

300

301

302

303

304

305

306

307

308

309

310

311

312

313

314

315

316

data are not constant and they are not available every year and, in certain years, data is estimated by the relevant municipal department, IOM result is verified and corrected by key stakeholders.

The stakeholders are related to the main vulnerable sectors: urban water supply, communication and information, transportation, energy supply, sewage and drainage, solid waste collection and treatment, health, insurance, urban green and biodiversity, food production and supply, buildings and build-up area, governance and management, poverty reduction and management and tourism. The preliminary IOM on priority climatic threats in Beijing is presented in Fig 3, which shows that the priority climatic threats in Beijing are urban drainage floods, high temperature and heat waves and water scarcity and drought. Therefore the main sources for adapting to climate change in Beijing are suggested to allocate means to increase adaptive capacities of responding to heavy rain and drainage floods, high temperature and heat waves and to solve the consequences of water scarcity after droughts. Other climatic threats such as heavy snow and frost, windstorm, wildfires, may be also included in the urban adaption action plan by allocating certain resources, e.g. finance and services.

\section{(Data source: primary data)}

Fig 3 Priority climatic threats in Beijing

3.2 Vulnerable sectors and groups in each of the priority climate schemes

For identifying vulnerable sectors and groups, a one day workshop that has been described in the section 2 of this paper was organized. At the end of the workshop day, each participant made his or her own selection of vulnerable sectors and groups. Based on the selection of each participant, the research team determines the aggregate average score, and the final result is based on the aggregate average score, which is presented in table 3 and table 4.

Table 3 Vulnerable sectors and climatic threats (score: 1-10, high score, high vulnerability) (Data source: primary data)

Table 3 shows the most vulnerable sectors are water supply, waste management, health, energy supply and tourism in the case of high temperature and heat waves, and sewage, waste management, health, insurance, build-up area, transportation and tourism in the case of drainage and floods, and water supply, insurance, health and forest and ecosystem in the case of water scarcity and drought. Aggregate average scores in table 3 show that there is no significant difference among most sectors in vulnerability to climate change, since the coefficient of variation (C.V.) is $13.0 \%$ that is less than $15 \%$. Significant difference exists in each of the climatic threats, since $\mathrm{CV}$ is $31.8 \%$ in the case of heatwave, $27.8 \%$ in the case of floods and $48.4 \%$ in the case of drought. . The research result suggests the municipality of Beijing should take an integrated approach to climate adaptation, instead of sectoral actions. 
Table 4 Vulnerable groups and climatic threats (score: 1-10, high score, high vulnerability) (Data source: primary data)

Table 4 provides that there is no significant difference of vulnerability among different groups and different climatic threats, except ethnic minorities that have no difference with majorities in Beijing in terms of living standards and lifestyles. Therefore it is suggested that adaptation action in Beijing will be targeting vulnerable groups of elderly, sick, disabled, children and, in particular low-income and outdoor workers.

\subsection{UVI in each of priority climate threats}

An urban vulnerability index (UVI) that measures vulnerability to climate changes is a crucial part of the adaptation capacity building process. An UVI is an assessment, information and monitoring tool. As an assessment tool, it helps identify risks and vulnerabilities. As an information tool, it can better instruct the design of early-warning systems and adaptation action plan as well as raise awareness and communicate about vulnerability and risks. As a monitoring tool, it can identify how well a city has responded and recovered to disasters and shocks and whether the targets have been met. Hence, an UVI plays a role during the whole adaptation capacity building process. By applying the three-dimension framework presented in Fig 2, together with literature reviews and expert approach, the composite UVI is presented in the table 5 .

Table 5 Composite UVI in different climatic threats in Beijing Note: The values in brackets are the weights.

Fig 4 presents data of vulnerability for the climatic threat of drainage floods in the 16 districts of Beijing. It shows that the vulnerability in 2016 increases significantly (T-test result: $\mathrm{T}=24.82>$ $\mathrm{T}(\mathrm{a}=0.05, \mathrm{n}-2=7)=2.365)$ by $5 \%-10 \%$ compared to 2008 , except the district of Shunyi, where the Beijing Capital International Airport is located and where its vulnerability decreased in the past 10 years, due to the high level drainage infrastructure, which has been developed in the airport area and industrial parks near the airport. High vulnerability to the threat of drainage of floods is observed in the urban core areas (downtown) of two districts of Dongcheng and Xicheng, due to the factors of high percentage of paved areas (high sensibility), high population density and high percentage of population above 65 years (high exposure) and old or very old urban drainage system (lower adaptive capacity) that was built 40 years ago.

Fig 4 Vulnerability to climatic threat of drainage floods

(Data source: primary data) 
357 Data of vulnerability for the climatic threat of high temperature and heat waves is presented in

358

359

360

361

362

363

364

365

366

367

368

369

370

371

372

373

374

375

376

377

378

379

380

381

382

383

384

385

386

387

388

389

390

391

392

393

394

395

396
Fig 5 Vulnerability to the climatic threat of high temperature and heat waves (Data source: primary data)

Fig 6 shows data of vulnerability for the climatic threat of drought in the 16 districts of Beijing. Fig 6 clearly indicates that vulnerability to drought in 2016 increased significantly (T-test result: $\mathrm{T}=12.90>\mathrm{T}(\mathrm{a}=0.05, \mathrm{n}-2=7)=2.365)$ by about $10 \%$ compared to 2008 in the districts of urban new development area and particularly in the four districts of urban ecological conservation area, but decreases by about $10 \%$ in the urban core areas and urban extended areas. The climatic threat of drought mainly influences the urban ecosystem and the sectors of agriculture and tourism, due to high sensibility and exposure in those areas and its impact in the urban downtown areas is limited, due to lower sensibility and exposure.

Fig 6 Vulnerability to the climatic threat of drought

(Data source: primary data)

Beijing integrated vulnerability index is calculated by the average of the sum of vulnerabilities of climatic threats of floods, heat waves and drought. Fig 7 presents that the integrated vulnerability in the 16 districts increased significantly ( $T$-test result: $\mathrm{T}=22.69>\mathrm{T}(\mathrm{a}=0.05, \mathrm{n}-2=7)=2.365)$. The UVI in the case of heat waves is highest and it is obviously increasing during the period of $2008-2016$, given to the factors of increasing sensibility (e.g. increasing of numbers of day and night of heat waves annually, limited green space, and increasing of high-rise buildings) and of exposure (e.g. increasing of population density and population above 65 years old, increasing of outdoor workers). Although adaptive capacity in all 16 districts is increasing, the increase is not enough to overcome the increase in both sensibility and exposure. The integrated UVI in the case 
397

398

399

400

401

402

403

404

405

406

407

408

409

410

411

412

413

414

415

416

417

418

419

420

421

422

423

424

425

426

427

428

429

430

431

432

433

434

435

436

drought is almost stabilized, due to that fact that this UVI decreases in the urban core areas and increases in the urban outskirt of ecological conservation areas. The integrated UVI in the case floods increases slowly, due to the fact that the increase of both sensibility and exposure increases the UVI and the improvement of urban drainage services and governance capacity decreases the UVI.

Fig 7 Integrated vulnerability to climate change in Beijing

(Data source: primary data)

\section{DISCUSSION}

The vulnerability assessment has dominated climate change adaptation programmes at various levels of community, city, region, country and the world as a whole [20, 21, 22]. All assessments are developed based on the definitions of vulnerability and this article is based on the IPCC definition. The IPCC definition defines three components of sensibility, exposure and adaptive capacity of vulnerability. The advantages of the IPCC definition are that it is easy to communicate and results can be compared. The limitation is that the three components lack policy relevance. For linking the assessment to adaptation policies and actions, multidimensional vulnerability has been defined and multi-dimensional vulnerability encompasses physical, economic, social, environmental and institutional features [23]. It is obvious that a multi-dimensional vulnerability assessment needs more indicators and data than the threedimensional model developed in this article. From definition to practical assessment, the most important challenge facing vulnerability assessments is how to contextualize a definition for the local level, community or district level and even street level. This article started from the 87 indicators selected from literature and, by contextualization, finally 23 indicators are selected for assessing vulnerability to climate change. We argue that the three-dimensional model requires limited indicators and data and thus it is better fitting with cities and communities where data is lacking.

The majority of vulnerability assessments focuses on international, national and regional levels and it is necessary to downscale to the community level for supporting local policy framing and adaptation actions [23, 24, 25]. In this article, the focus was on the city and district levels. We go beyond the IPCC framing of exposure, sensitivity and adaptive capacity by developing indicators for them. We have communicated this research results with local stakeholders and the feedback shows that vulnerability assessment on a grid scale is much needed, since it provides crucial information for policy makers and stakeholders to take local actions. We argue that, for improving policy relevance and intensifying linkages of the assessment and local action, urban vulnerability assessments need to downscale to the street level. In this regard, combining IBVA with GIS is called for in the future, since GIS could provide data on very small scale, e.g. on scale of one $\mathrm{km}^{2}$. 
437

438

439

440

441

442

443

444

445

446

447

448

449

450

451

452

453

454

455

456

457

458

459

460

461

462

463

464

465

466

467

468

469

470

471

472

473

474

475

476

477

In this research the Impact Oriented Monitoring (IOM) together with stakeholders' participation is proven effective to define priority climatic threats. Applying IOM requires collection of highquality historical data. IOM could provide direct effects of climate disaster and thus it help to communicate with policy makers and stakeholders and helps to understand climate threats that a city may face. By applying IOM, priority climate threats have been identified and thus we capture the key features of vulnerability. Hence it provides valuable and reliable information on vulnerability to difference climatic threats at the city and district level.

The selection of primary indicators is based on a literature study and the reduction and weighting of indicators were the result of a combined experts' opinions, stakeholders' participation and using AHP. There are limitations in aggregating weighted indicators using the additive approach that is mainly based on Multiple Attribute Utility Theory (MAUT) [8]. Indicators should be independent and there should be a precise mathematical relationship between indicators. In the literature, most indicator-based vulnerability assessments use MAUT for aggregation of indicator despite the fact that IBVA rarely satisfies MAUT. In our study, we have introduced the criterion of indicator independence in the preliminary selection of indicators. We argue that MAUT is applicable to aggregation of indicators, since all IBVA in vulnerability studies are empirical. However one must be very careful to explain and communicate the IBVA results, since IBVA provides information more on variations of vulnerability to climate change as indicated in figures 4 to 7 . IBVA hardly provides information on the absolute value of vulnerability.

The results generated by this research indicate that Beijing is highly exposed to multiple climate threats in the context of global climate change, specifically urban high temperature and heat waves, heavy rain and urban drainage floods and reduced precipitation and drought. This vulnerability assessment, which addressed priority climatic threats in Beijing, provides a holistic understanding of the susceptibility to climate change that could be a guidance for facilitating future adaptation.

\section{CONCLUSIONS}

The following key conclusions could help explain the vulnerability to climate change in Beijing.

1) The IOM result depicted in Fig 2 shows that priority climatic threats are urban drainage floods, high temperature and heat waves and water scarcity and drought in Beijing. Therefore the main source for adapting to climate change in Beijing is increasing the adaptive capacity to be able to respond to heavy rains and drainage floods, high temperature and heat waves and water scarcity and drought. The IOM results revealed that the most harmful climatic threat was historically urban floods in Beijing. However this is changing recently and high temperature and heat waves are going to be the most harmful climatic threat as indicated in Fig 6.

2) Vulnerability to high temperature and heat waves in 2016 increased significantly by $10 \%-15 \%$ in all 16 districts of Beijing compared to 2008. High vulnerability to heat waves is observed

PeerJ reviewing PDF | (2019:02:35170:2:1:NEW 23 Apr 2019) 
478

479

480

481

482

483

484

485

486

487

488

489

490

491

492

493

494

495

496

497

498

499

500

501

502

503

504

505

506

507

508

509

510

511

512

\section{REFERENCES}

514 [1] UNFCCC. (2015). Paris agreement (Vol. FCCC/CP/20). Bonn.

515 [2] Magnan, A. K., Ribera, T. (2016). Global adaptation after Paris. Science, 352(6291), 1280-1282.

516 [3] Ford, J., Berrang-Ford, L. (2016). The 4Cs of adaptation tracking: Consistency, comparability,

517 comprehensiveness, coherency. Mitigation and Adaptation Strategies for Global Change, 21(6), 839-859. 
518 [4] IPCC, 2014: Climate Change 2014: Synthesis Report. Contribution of Working Groups I, II and III to 519 the Fifth Assessment Report of the Intergovernmental Panel on Climate Change [Core Writing Team, 520 R.K. Pachauri and L.A. Meyer (eds.)]. IPCC, Geneva, Switzerland, 79-80.

521 [5] Birkmann, J. 2007. Risk and vulnerability indicators at different scales: applicability, usefulness and 522 policy implications. Environmental Hazards, 7, 20-31.

523 [6] El-Zein, A. \& Tonmoy, F. N. 2015. Assessment of vulnerability to climate change using a multi-

524 criteria outranking approach with application to heat stress in Sydney. Ecological Indicators, 48, 207-217.

525 [7] Bollin, C., Hidajat, R., 2006. Community-based disaster risk index: pilot implementation in Indonesia.

526 In: Birkmann, J. (Ed.), Measuring Vulnerability to Natural Hazards - towards Disaster Resillient

527 Societies. UNU-Press. Tokyo, New York, Paris.

528 [8] Tonmoy, F. N., El-Zein, A. \& Hinkel, J. 2014. Assessment of vulnerability to climate change using

529 indicators: a meta - analysis of the literature. Wiley Interdisciplinary Reviews: Climate Change, 5, 775-

530792.

531 [9] Amaru, S., Chhetri, N. B. (2013). Climate adaptation: Institutional response to environmental

532 constraints, and the need for increased flexibility, participation, and integration of approaches. Applied

533 Geography, 39, 128-139.

534 [10] IPCC, Fourth Assessment Report Climate Change (2007), Impacts, Adaptation and Vulnerability

535 Contribution of Working Group II to the Fourth Assessment Report of the IPCC, Cambridge University

536 Press, 2007.

537 [11] Patt, A.G., M. Tadross, P. Nussbaumer, K. Asante, M. Metzgere, J. Rafael, A. Goujona, and

538 G.Brundriti (2009a). Estimating least - developed countries' vulnerability to climate - related extreme

539 events over the next 50 years.

540 [http://www.pnas.org/content/early/2009/12/15/0910253107.abstract]

541 [12] Yohe, G.W. and Tol, R.S.J. (2002). Indicators for social and economic coping capacity - moving

542 toward a working definition of adaptive capacity. Global Environmental Change 12, pp. 25 - 40.

543 [13] Brooks, N., Adger, W.N., Kelly, P.M. (2005). The determinants of vulnerability and adaptive

544 capacity at the national level and the implications for adaptation. Global Environmental Change, 15 (2),

545 pp. $151-163$.

546 [14] Vincent K. (2004). Creating an index of social vulnerability to climate change for Africa. Tyndall

547 Centre for Climate Change Research, Working Paper 56, Norwich.

548 [http://www.tyndall.ac.uk/publications/working_papers/wp56.pdf]

549 [15] Van Dijk, M.P., Zhang, M., (2005) Sustainability indices as a tool for urban managers, Evidence

550 from four medium-sized Chinese cities. Environmental Impact Assessment Review, Vol. 25, 667-89.

551 [16] European Environment Agency, 2018, National climate change vulnerability and risk assessments in

552 Europe, 2018, EEA Report, No 1/2018, ISSN 1977-8449, Page 52.

553 [17] Kropp, J., Holsten, A., Lissner, T., Roithmeier, O., Hattermann, F., Huang S., Rock J. and

554 Metzger, M (2009). Klimawandel in Nordrhein - Westfalen - Regionale Abschätzung der Anfälligkeit

555 ausgewählter Sektoren. Abschlussbericht des Potsdam - Instituts für Klimafolgenforschung (PIK) für das

556 Ministerium für Umwelt und Naturschutz, Landwirtschaft und Verbraucherschutz Nordrhein - Westfalen

557 (MUNLV). [http://www.umwelt.nrw.de/umwelt/pdf/abschluss_pik_0904.pdf]

558 [18] Van Dijk, M.P. (2014) Measuring eco cities, comparing European and Asian experiences: Rotterdam

559 versus Beijing. Asia Europe journal, DOI: 10.1007/s10308-014-0405-7. 
560 [19] World Economic Forum, 2001, Environmental Sustainability Index, an Initiative of the Global

561 Leaders of Tomorrow Environment Task Force, World Economic Forum, Annual Meeting 2001, Davos, 562 Switzerland.

563 [20] Hinkel, J. (2011). Measuring vulnerability and adaptive capacity: towards a clarification of the

564 science - policy interface. Global Environmental Change 21, pages 198 -208.

565 [21] Sheridan S.C., Kalkstein, L. S., Progress in heat watch-warning system technology [J], Bulletin of

566 the American Meteorological Society, 2004, 85 (12).

567 [22] Ford, J., Berrang-Ford, L., Biesbroek, R., Araos, M., Austin, S., Lesnikowski, A. (2015). Adaptation 568 tracking for a post-2015 climate agreement. Nature Climate Change, 5, 967-969.

569 [23] Birkmann, J., 2005. Danger need not spell disaster - but how vulnerable are we? Research Brief, 570 Number I, United Nations University. Tokyo.

571 [24] Lesnikowski, A., Ford, J., Berrang-Ford, L., Barrera, M., Heymann, J. (2015). How are we adapting 572 to climate change? A global assessment. Mitigation and Adaptation Strategies for Global Change, 20(2), 573 277-293.

574 [25] Adger, W. N., 2006, "Vulnerability". Global Environmental Change 16 (3): 268-281.

575 [26] Yuen, E., S. Jovicich, B. Preston. 2013. Climate change vulnerability assessments as catalysts for 576 social learning: four case studies in south-eastern Australia. Mitigation and Adaptation Strategies for 577 Global Change 18:567-590. 
Figure $\mathbf{1}$ (on next page)

Procedures for the assessment and methodology for data collection 
Procedures

Methodology

Identification of priority

climate themes

Impact Oriented

Monitoring (IOM)
Identification of vulnerable

sectors and groups

Development of

assessment framework

Selection and weighting of indicators

\section{Stakeholder \\ participation}

\section{Literature study and \\ Fuzzy analysis (AHP)}


Figure 2 (on next page)

AHP framework for measuring urban sensibility for the threat of floods 


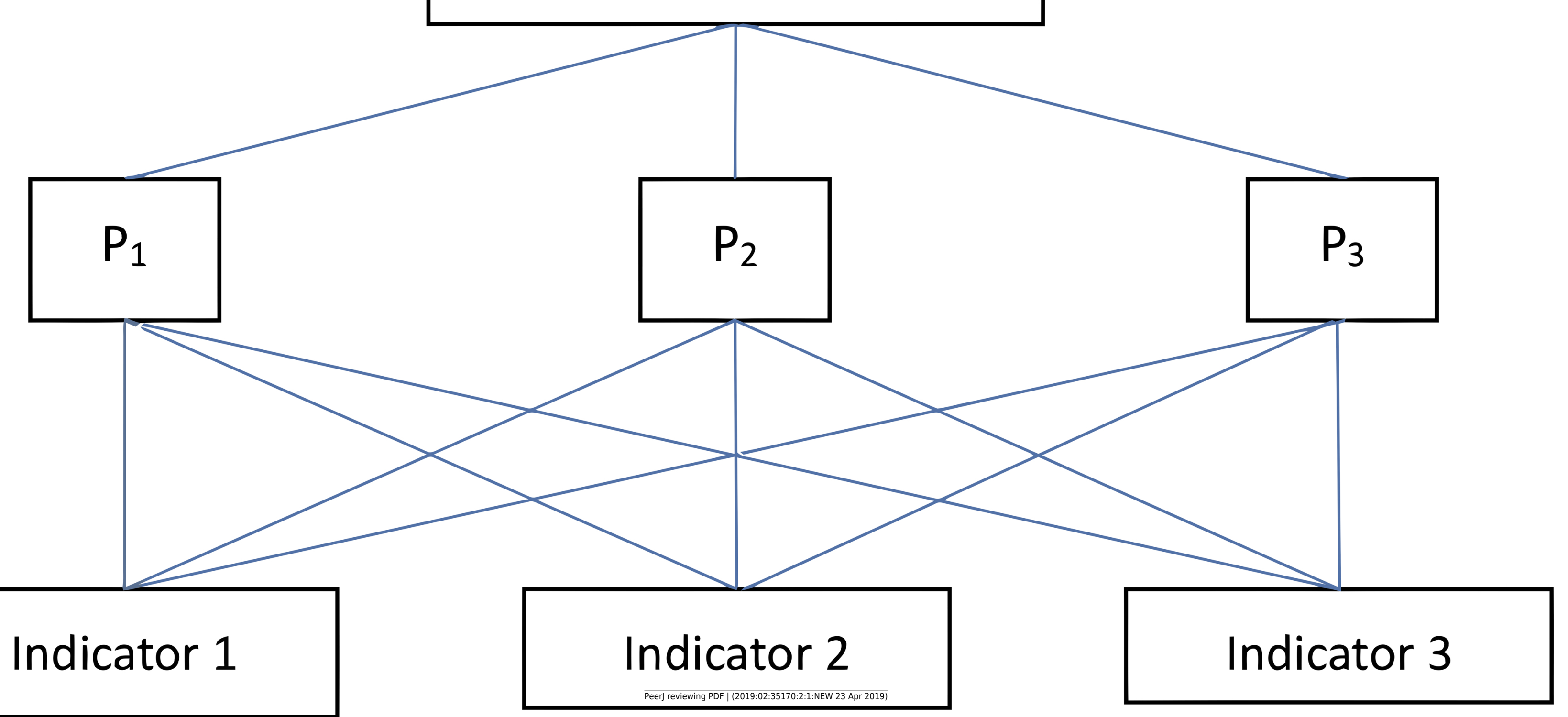

Principles

Indicators 
Figure 3 (on next page)

Priority climatic threats in Beijing 


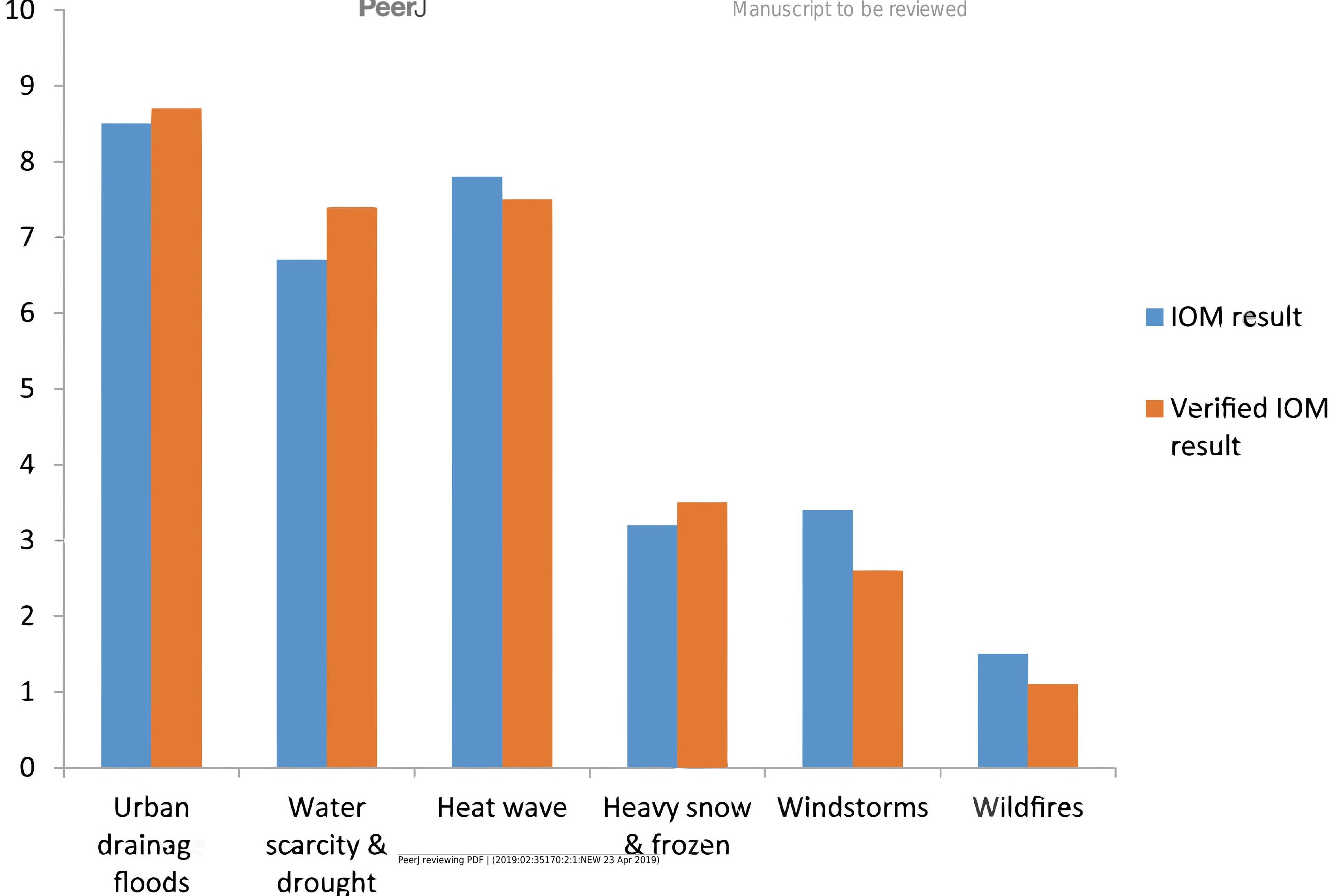


Figure 4 (on next page)

Vulnerability in the climatic thread of drainage floods 


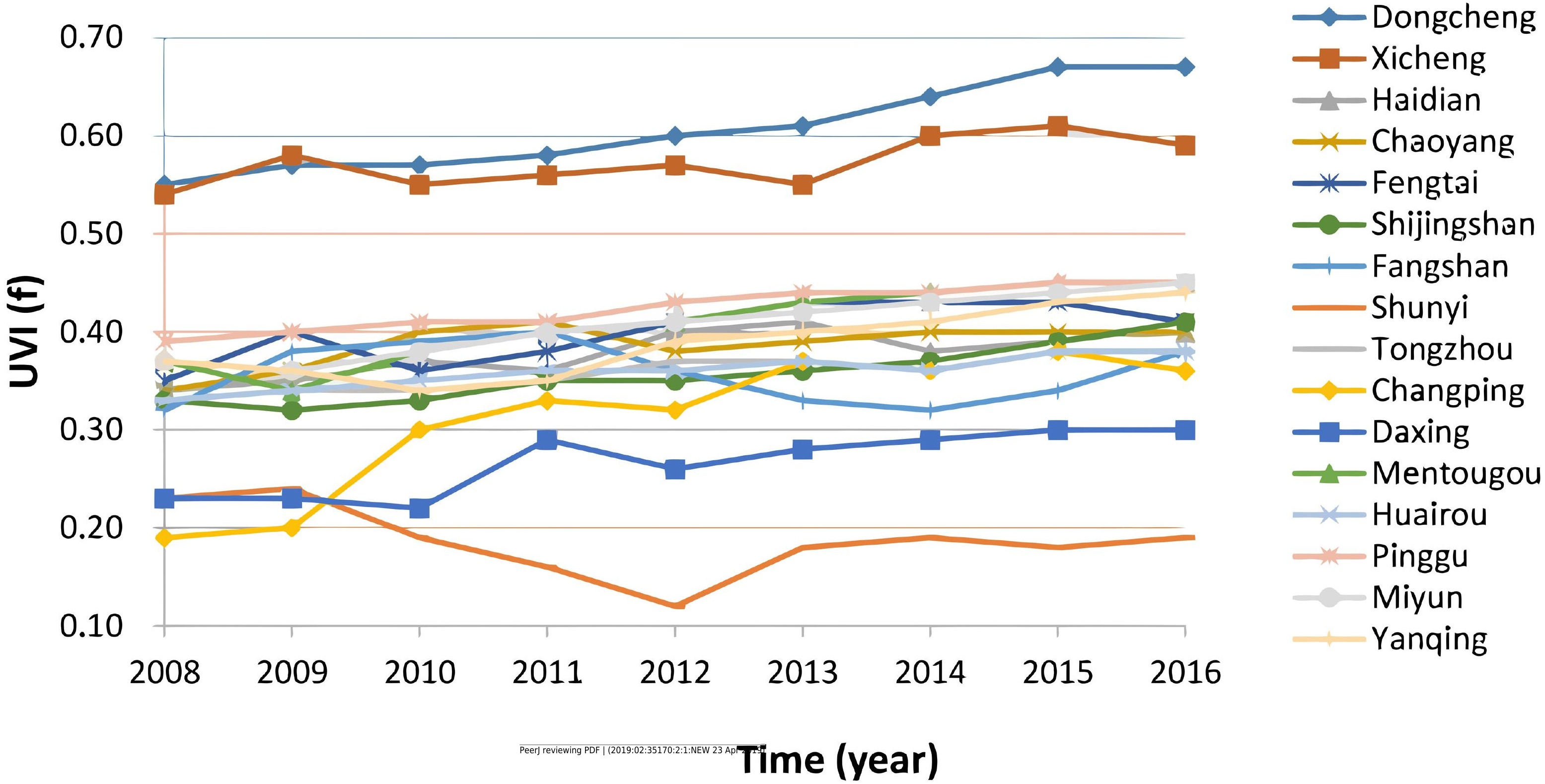


Figure $\mathbf{5}$ (on next page)

Vulnerability in the climatic thread of high temperature and heat waves 


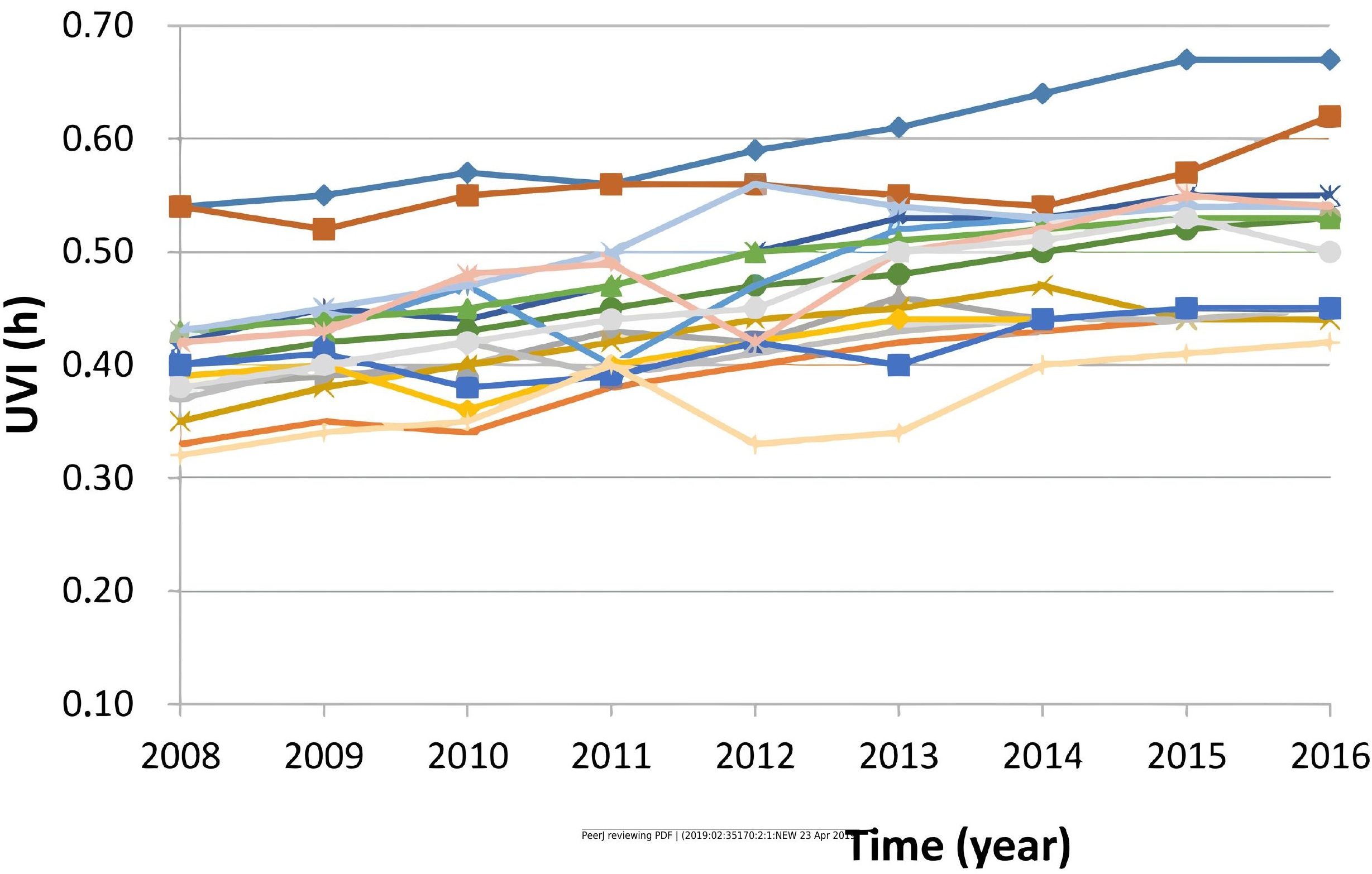

Dongcheng

-Xicheng

$-\mathrm{H}$ idian

*Chaoyang

* Fengtai

- Shijingshan

- Fangshan

Shunyi

-Tongzhou

—Changping

-Daxing

- Mlentougou

$x$ Huairou

Pinggu

Miyun

Yanqing 
Figure 6 (on next page)

Vulnerability in the climatic thread of drought 
Figure 7 (on next page)

Integrated vulnerability to climate change in Beijing 
0.50

0.40

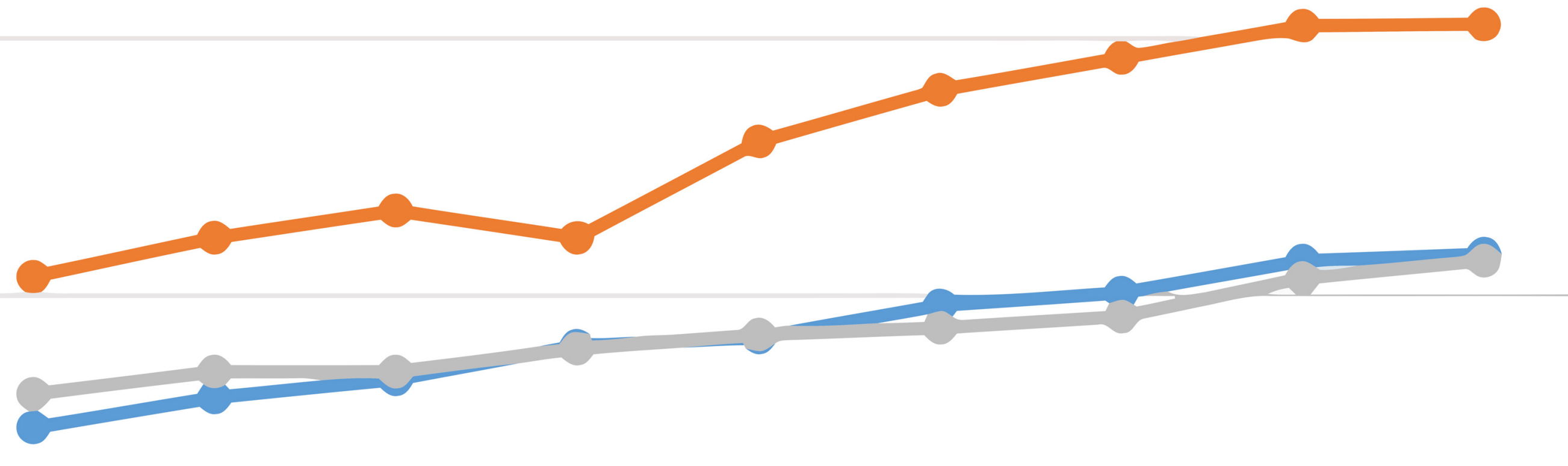

$\longrightarrow$ UVI(floods)

-UVI(heatwave)

- UVI(drought)

0.30

0.20

$\begin{array}{lllllll}2008 & 2009 & 2010 & 2011^{2} & 2015 & 2016\end{array}$


Table $\mathbf{1}$ (on next page)

Values of comparison between two factors 
1

2

3
Table 1 Values of comparison between two factors

\begin{tabular}{lc}
\hline Description & Value of A/B \\
\hline 1. as important as B & 1 \\
2. between 1 and 3 & 2 \\
3. slightly more important than B & 3 \\
4. between 3 and 5 & 4 \\
5. really more important than B & 5 \\
6. between 5 and 7 & 6 \\
7. much more important than B & 7 \\
8. between 7 and 9 & 8 \\
9. very much more important than B & 9 \\
\hline
\end{tabular}

4

5 
Table 2 (on next page)

Four areas and 16 districts under this research 
1 2

Table 2 Four areas and 16 districts under this research

\begin{tabular}{|c|c|c|}
\hline 4 areas & Main function & 16 districts \\
\hline $\begin{array}{l}\text { Urban core area (city } \\
\text { centre) }\end{array}$ & $\begin{array}{l}\text { downtown and location of } \\
\text { central government }\end{array}$ & 2 districts: Dongcheng and Xicheng \\
\hline Urban extended area & Main developed area & $\begin{array}{l}4 \text { districts: Haidian, Chaoyang, Fengtai and } \\
\text { Shijingshan }\end{array}$ \\
\hline $\begin{array}{l}\text { Urban new } \\
\text { development area }\end{array}$ & Areas for new development & $\begin{array}{l}5 \text { districts: Fangshan, Shunyi, Tongzhou, } \\
\text { Changping and Daxing }\end{array}$ \\
\hline $\begin{array}{l}\text { Ecological } \\
\text { conserving area }\end{array}$ & $\begin{array}{l}\text { Limited development and } \\
\text { providing ecological } \\
\text { services to the city }\end{array}$ & $\begin{array}{l}5 \text { districts: Mentougou, Huairou, Pinggu, Miyun } \\
\text { and Yanqing }\end{array}$ \\
\hline
\end{tabular}

3

4 


\section{Table $\mathbf{3}$ (on next page)}

Vulnerable sectors and climatic threats (score: 1-10, high score, high vulnerability) 
1

Table 3 Vulnerable sectors and climatic threats (score: 1-10, high score, high vulnerability)

\begin{tabular}{lcccc}
\hline & Heatwave & Floods & Drought & Average \\
\hline Water supply & 7.5 & 4.4 & 7.0 & 6.3 \\
Sewage & 4.7 & 8.9 & 2.6 & 5.4 \\
Waste management & 7.3 & 8.1 & 1.8 & 5.7 \\
Heath & 8.4 & 7.3 & 6.5 & 7.4 \\
Insurance & 4.4 & 7.9 & 6.8 & 6.4 \\
Energy supply & 8.8 & 4.2 & 5.2 & 6.1 \\
Build-up areas & 3.5 & 7.2 & 2.8 & 4.5 \\
Transportation & 6.2 & 7.8 & 3.3 & 5.8 \\
Forest and ecosystem & 3.8 & 3.7 & 8.0 & 6.3 \\
Tourism & 7.7 & 6.8 & 2.8 & 5.4 \\
\hline Statistical Analysis & & & & \\
\hline Mean & 6.2 & 6.6 & 4.7 & 5.9 \\
Standard deviation (SD) & 1.98 & 1.84 & 2.26 & 0.77 \\
Coefficient of variation (SD/Mean $\times 100 \%)$ & $31.8 \%$ & $27.8 \%$ & $48.4 \%$ & $13.0 \%$ \\
\hline
\end{tabular}

(Data source: primary data) 


\section{Table 4 (on next page)}

Vulnerable groups and climatic threats (score: 1-10, high score, high vulnerability) 
1

2

Table 4 Vulnerable groups and climatic threats (score: 1-10, high score, high vulnerability)

\begin{tabular}{llllllll}
\hline & Elderly & Sick & Disabled & Child & $\begin{array}{l}\text { Low- } \\
\text { income }\end{array}$ & $\begin{array}{l}\text { Ethnic } \\
\text { minorities }\end{array}$ & $\begin{array}{l}\text { Outdoor } \\
\text { workers }\end{array}$ \\
\hline Heatwave & 8.8 & 8.2 & 6.8 & 7.3 & 7.7 & 2.5 & 9.3 \\
Floods & 4.5 & 5.2 & 7.4 & 5.7 & 6.9 & 2.0 & 8.3 \\
Drought & 3.7 & 7.4 & 3.8 & 3.2 & 6.8 & 2.8 & 3.2 \\
Average & 5.7 & 6.9 & 6.0 & 5.4 & 7.1 & 2.5 & 6.9 \\
\hline
\end{tabular}

3 (Data source: primary data) 
Table 5 (on next page)

Composite UVI in different climatic threats in Beijing 
Table 5 Composite UVI in different climatic threats in Beijing

\begin{tabular}{|c|c|c|}
\hline Urban vulnerability index & Sensibility Index $\left(I_{s}\right)$ & $\mathrm{I}_{1}:$ Annual rainstorm hours $(0.45)$ \\
\hline in the thread of floods & $(0.30)$ & $\mathrm{I}_{2}:$ Percentage of paved area $(0.35)$ \\
\hline$\left(\mathrm{UVI}_{\mathrm{f}}\right)$ & & $\mathrm{I}_{3}$ : Risk of secondary disasters caused by heavy \\
\hline $\mathrm{UVI}_{\mathrm{f}}=0.3 \mathrm{I}_{\mathrm{s}}+0.3 \mathrm{I}_{\mathrm{e}}-0.4 \mathrm{I}_{\mathrm{a}}$ & & precipitation $(0.20)$ \\
\hline & Exposure Index $\left(\mathrm{I}_{\mathrm{e}}\right)$ & $\mathrm{I}_{4}$ : Percentage of population above 65 years old $(0.63)$ \\
\hline & $(0.30)$ & $\mathrm{I}_{5}:$ Population density $(0.37)$ \\
\hline & Adaptive capacity $\left(I_{a}\right)$ & $\mathrm{I}_{6}:$ Governance capacity $(0.35)$ \\
\hline & $(0.40)$ & $\mathrm{I}_{7}$ : Capacity and quality of drainage infrastructure $(0.40)$ \\
\hline & & $\mathrm{I}_{8}$ : Capacity of early warning $(0.25)$ \\
\hline Urban vulnerability index & Sensibility Index $\left(I_{s}\right)$ & $\mathrm{I}_{1}:$ Percentage of high-rise building $(0.15)$ \\
\hline in the thread of heatwave & $(0.30)$ & $\mathrm{I}_{2}:$ Numbers of days\&nights of heatwaves $(0.50)$ \\
\hline$\left(\mathrm{UVI}_{\mathrm{h}}\right)$ & & $\mathrm{I}_{3}:$ Percentage of urban green area $(0.35)$ \\
\hline $\mathrm{UVI}_{\mathrm{h}}=0.3 \mathrm{I}_{\mathrm{s}}+0.3 \mathrm{I}_{\mathrm{e}}-$ & & \\
\hline $0.4 \mathrm{I}_{\mathrm{a}}$ & Exposure Index $\left(\mathrm{I}_{\mathrm{e}}\right)$ & $\mathrm{I}_{4}$ : Percentage of population above 65 years old $(0.23)$ \\
\hline & $(0.30)$ & $\mathrm{I}_{5}:$ Percentage of low income $(0.31)$ \\
\hline & & $\mathrm{I}_{6}:$ Percentage of outdoor workers $(0.46)$ \\
\hline & Adaptive capacity $\left(I_{a}\right)$ & $\mathrm{I}_{7}:$ Governance capacity $(0.55)$ \\
\hline & $(0.40)$ & $\mathrm{I}_{8}$ : Capacity of early warning $(0.45)$ \\
\hline Urban vulnerability index & Sensibility Index $\left(I_{s}\right)$ & $\mathrm{I}_{1}:$ Average annual precipitation $(0.55)$ \\
\hline in the thread of drought & $(0.30)$ & $\mathrm{I}_{2}:$ Days of daily precipitation of less than $0.1 \mathrm{~mm}(0.45)$ \\
\hline$\left(\mathrm{UVI}_{\mathrm{d}}\right)$ & & \\
\hline $\mathrm{UVI}_{\mathrm{d}}=0.3 \mathrm{I}_{\mathrm{s}}+0.3 \mathrm{I}_{\mathrm{e}}-0.4 \mathrm{I}_{\mathrm{a}}$ & Exposure Index $\left(\mathrm{I}_{\mathrm{e}}\right)$ & $\mathrm{I}_{3}$ : Biodiversity $(0.30)$ \\
\hline & $(0.30)$ & $\mathrm{I}_{4}$ : Percentage of population above 65 years old $(0.33)$ \\
\hline & & $\mathrm{I}_{5}$ : Share of agricultural GDP in total GDP $(0.37)$ \\
\hline & Adaptive capacity $\left(I_{a}\right)$ & $\mathrm{I}_{6}:$ Governance capacity $(0.55)$ \\
\hline & $(0.40)$ & $\mathrm{I}_{7}$ : Capacity of early warning $(0.45)$ \\
\hline
\end{tabular}

2 Note: The values in brackets are the weights. 